\title{
WATER ABSORPTION PROPERTIES OF HEMP FIBRES REINFORCED PLA BIO-COMPOSITES
}

\author{
Anete Smoca \\ Riga Technical University, Latvia \\ aneteu@gmail.com
}

\begin{abstract}
In the development of a sustainable economy more and more emphasis is put on the development of new materials based on natural resources. Hemp fibers are one of the most environmentally friendly natural fibers with high tensile strength, retained moisture strength and other properties that make them suitable for a wide variety of industrial products. The advantage of extracting hemp fibers is that it is possible to use all parts of the plant at the same time for the production of different products - hemp seeds, their shells, hemp shives, thus maximizing the value added of this resource (the concept of sustainable development). Industrial production based on non-renewable resources, increasing demand in the consumer sphere, rapidly growing population and density puts increasing pressure on planetary resources. In this research project a biodegradable composite material is made from hemp fiber and polylactide (polymerized corn starch). Thermoset treated polylactic and hemp fiber bio-composites have high mechanical properties, which allow to reduce the amount of materials in the product. The developed bio-composite can be used both as a slab material and for molded parts of furniture, etc. In this study 3 samples of bio-composite materials with different proportion of hemp fibres in the PLA matrix were compared and their water absorption was investigated. Bio-composite hemp and polylactide (PLA) fibres were evenly blended using the carding technology. The obtained blanks were treated for thermosetting at a fixed temperature of $180{ }^{\circ} \mathrm{C}$ and a pressure of $100 \mathrm{kN}$, as well as controlled heating, compression and cooling time was applied. Bio-composite samples were tested following the water absorption standard LVS EN ISO 62:2008. Obtained material is biodegradable during the composting process, which improves the ecological assessment (Life Cycle Assessment) of the product and reduces the environmental impact. Annually renewable hemp fiber resource has the potential to create new products and develop the hemp industry in Latvia.
\end{abstract}

Keywords: composite, biocomposite, hemp fibres, polylactide, PLA.

\section{Introduction}

Hemp fibres are one of the most durable natural fibres with a low relative extension. They have high tensile strength and moisture resistance. These qualities make it suitable for a variety of industrial products [1].

Although the physical properties of fibres are lower than those of artificial fibres (such as glass and carbon fibres), their potential uses are expanding. Currently, a large number of natural fibres are used in the areas of fibre boards and composites-manufacturing and the search for solutions to related problems is being sought [2].

Compared to other natural fibres, hemp has good insulation properties. Insulation materials are sufficiently refractory and do not cause toxic substances if burned. Hemp fibres are lightly toned, withstand UV radiation and have natural antibacterial properties [3]. The biological resistance and long service life of the hemp fibres remain even in seawater [4].

Recent research and development efforts have shown that PLA is also a high-value composite matrix material. Fibre reinforced PLA composites that are easily pressable and compressible in the alloy are $50 \%$ stronger and more durable than other fibre-reinforced thermoplastic composites that are already used in auto panels [5].

To avoid thermal degradation, the treatment temperature should be maintained to $200{ }^{\circ} \mathrm{C}$. Reinforcing with fibres is one way to enhance the thermal stability. Polylactide polymer is stiff and brittle, so it is necessary to use plasticizers to improve elongation and impact properties. Polylactides are fully biodegradable by hydrolysis to lactic acid, which is metabolized by microorganisms to water and carbon dioxide. When composted with other biomass, biodegradation occurs within two weeks, and the material fully disappears within 3 to 4 weeks [6].

The sources analyzed above show that there are several advantages to PLA's potential as a matrix for bio-composites. First of all, PLA is one of the most advanced biopolymers in terms of its commercialization. Secondly, PLA has excellent mechanical properties similar to polystyrene properties. Third, PLA can be processed with standard processing equipment below the temperature at which natural fibers begin to degrade. 
Recent studies show that modification of hemp fibers is important to reach higher absorption potential. The modification of hemp fibers considerably decreased the hygroscopicity of the composites. The reinforcement of the composites with alkali treated fibers resulted in the lowest water absorption values. Enzymatic treatment is also an efficient method to decrease the water absorption of the composite. The modification of the fibers with wood distillates had a less pronounced effect on the water absorption, when compared with other modification methods, but the difference between unmodified fibers and wood distillate treated fibers is yet substantial [7].

The application of wood distillates on the hemp fibers created a protective surface on the fibers that hindered the water penetration into the fibers [7].

\section{Materials and methods}

The carding machine MESDAN $L A B$ was used for preparation and mixing of raw fibre materials. A high-performance thermopress, which involves thermosetting of temperature, time and pressurecontrolled samples in a specific steel frame, was used for all samples.

For optimal fibre matrix blend these pre-treated materials were used: hemp fibre USO-31 separated from hemp shives, cut into $7-8 \mathrm{~cm}$ in length and PLA fibre TREVIRA® 400 with the fibre linear density $6.7 \mathrm{dtex}$ and the length $-60 \mathrm{~mm}$.

After carding, the density of the blank and the optimal volume of the mass in the mold were determined. Control by pressure and heat thermosetting was performed consisting of three stages - 3 minutes of warming the plates, 3 minutes of the thermosetting process and 3 minutes of the cooling process.

Bio-composite samples with three types of compositions were prepared (Fig. 1). For comparative analysis a $100 \%$ PLA sample was also prepared.

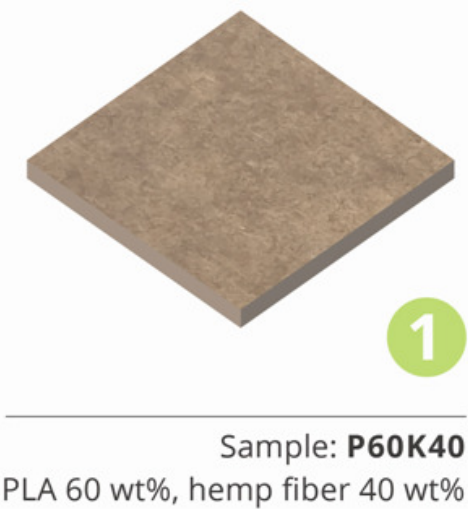

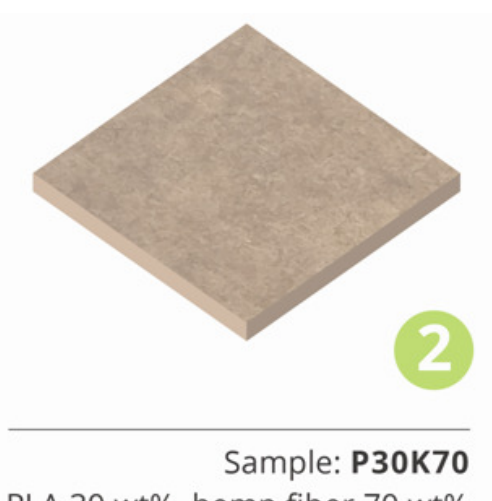

PLA 30 wt $\%$, hemp fiber 70 wt $\%$
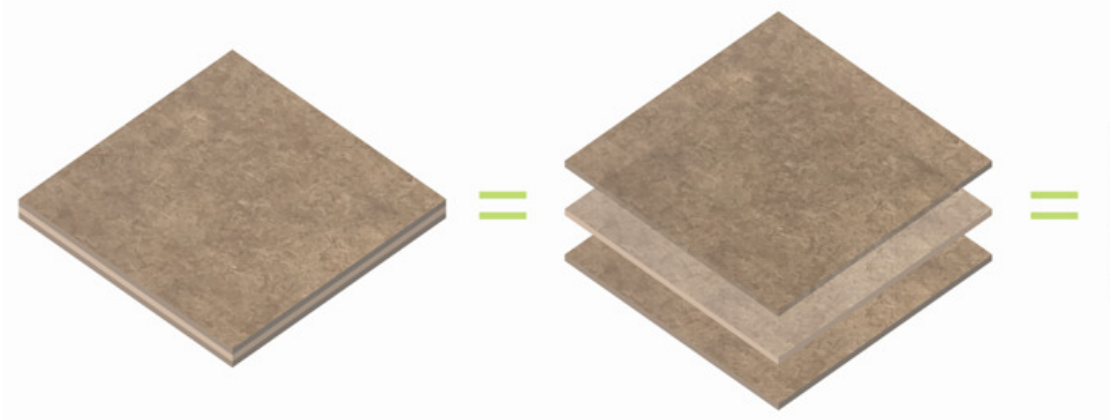

\begin{tabular}{|r|}
\hline PLA60/K40 \\
\hline PLA30/K70 \\
\hline PLA60/K40 \\
\hline
\end{tabular}

Sample: PLAKOMP

Outer sheets: PLA 60 wt $\%$, hemp fiber 40 wt $\%$ Inner sheets: PLA 30 wt $\%$, hemp fiber 70 wt $\%$

Fig. 1. Bio-composite samples (designation and composition) 
Bio-composite samples are made according to the manufacturing plan, which determines a fixed heat $180^{\circ} \mathrm{C}$ and the pressure $100 \mathrm{kN}$, as well as a controlled thermosetting process $\left(3^{\prime}\right.$ heating, $3^{\prime}$ pressing, $3^{\prime}$ cooling) for each sample. Samples of 2 bio-composite prototypes with dimensions of 150x150x $3 \mathrm{~mm}$ were made from each variant of the sample composition.

Bio-composite samples were tested following the water absorption standard LVS EN ISO 62:2008 [8]. Samples of the same size/vector were used for determination of water absorption. Sample thickness and weight vary. 5 samples of each type of material are used. Before the samples are immersed in water, they are dried for 24 hours at $105^{\circ} \mathrm{C}$ in the oven. After drying, the samples are weighed (accuracy to $0.01 \mathrm{~g}$ ) and immersed in a distilled water container at $23{ }^{\circ} \mathrm{C}$. Changes in the weight and thickness of the samples are recorded at certain time intervals: $1 ; 2 ; 5 ; 24 ; 48 ; 72 ; 96$ and 120 hours, etc. until the change of the mass of the composite samples practically no longer occurs.

The linear dimensions of the samples are determined with a digital gauge, with an accuracy of $0.01 \mathrm{~mm}$. The mass of material samples is determined by the electronic scales KERN KB.

The water content in the composite material is calculated by applying the mass change to the dry sample mass according to formula (1).

$$
W_{\bar{u}}=m_{t}-m_{o} / m_{o} \cdot 100 \%
$$

where $W_{\bar{u}}-$ water absorption;

$m_{t}-$ sample mass before drying, g;

$m_{o}-$ sample mass after drying, $\mathrm{g}$.

\section{Results}

The water absorption output data are summarized in the table and the results obtained are shown in the following graphs in Fig. 2 and Fig. 3.

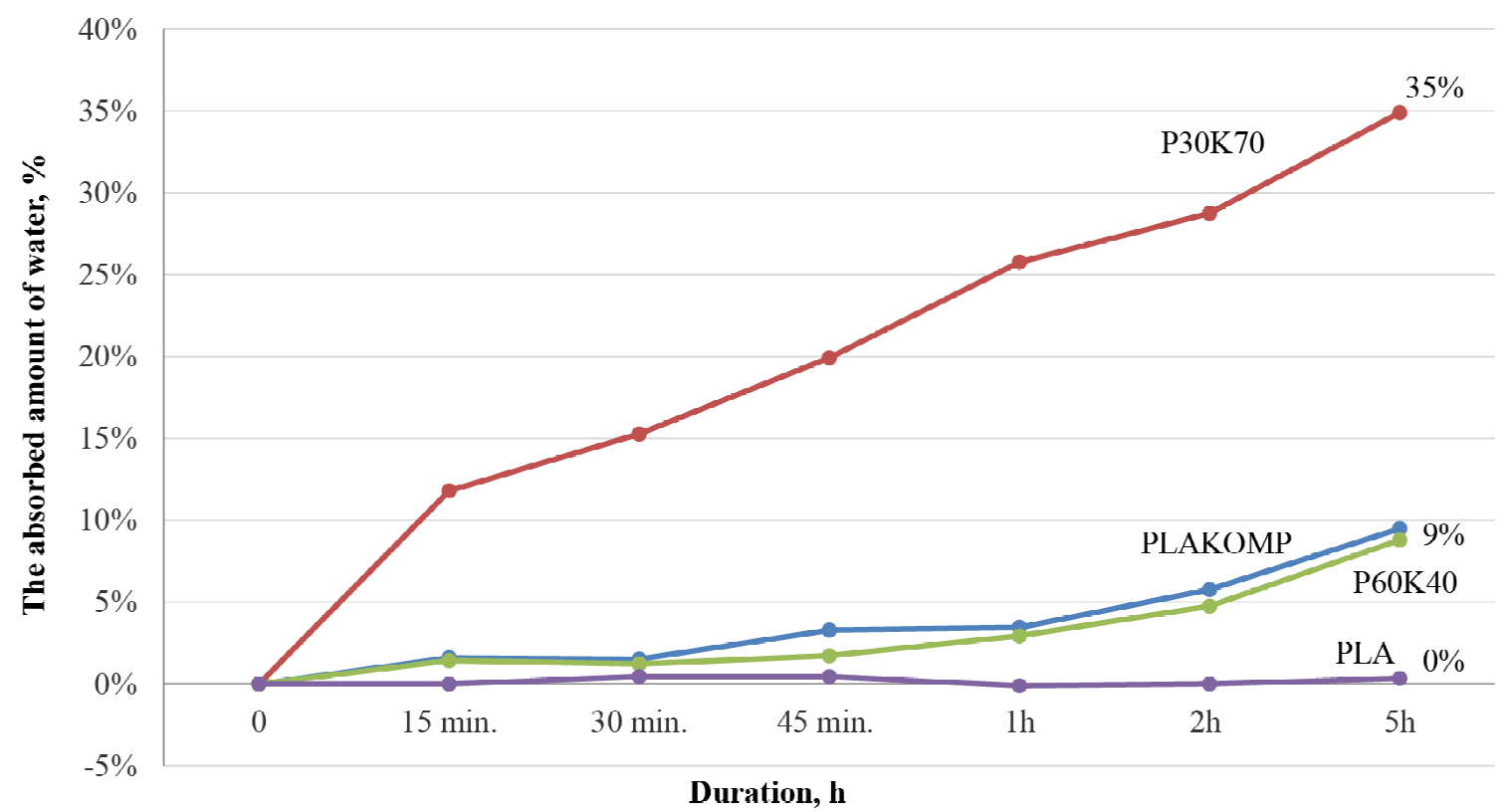

Fig. 2. Dynamics of amount of water absorbed during first 5 hours

Figure 2 shows that the sample P30K70, with $70 \%$ hemp fiber content, has a pronounced water absorption capacity compared to the rest of the samples - the water absorption capacity reaches $35 \%$ in the first 5 hours. This means that hemp fibers should be treated before incorporation to reduce their water absorption capacity.

In the PLAKOMP and P60K40 samples, the percentage of hemp fiber is much lower, respectively $50 \%$ and $40 \%$. In the first 5 hours, their absorption is less than $10 \%$ and is considered a good result. 


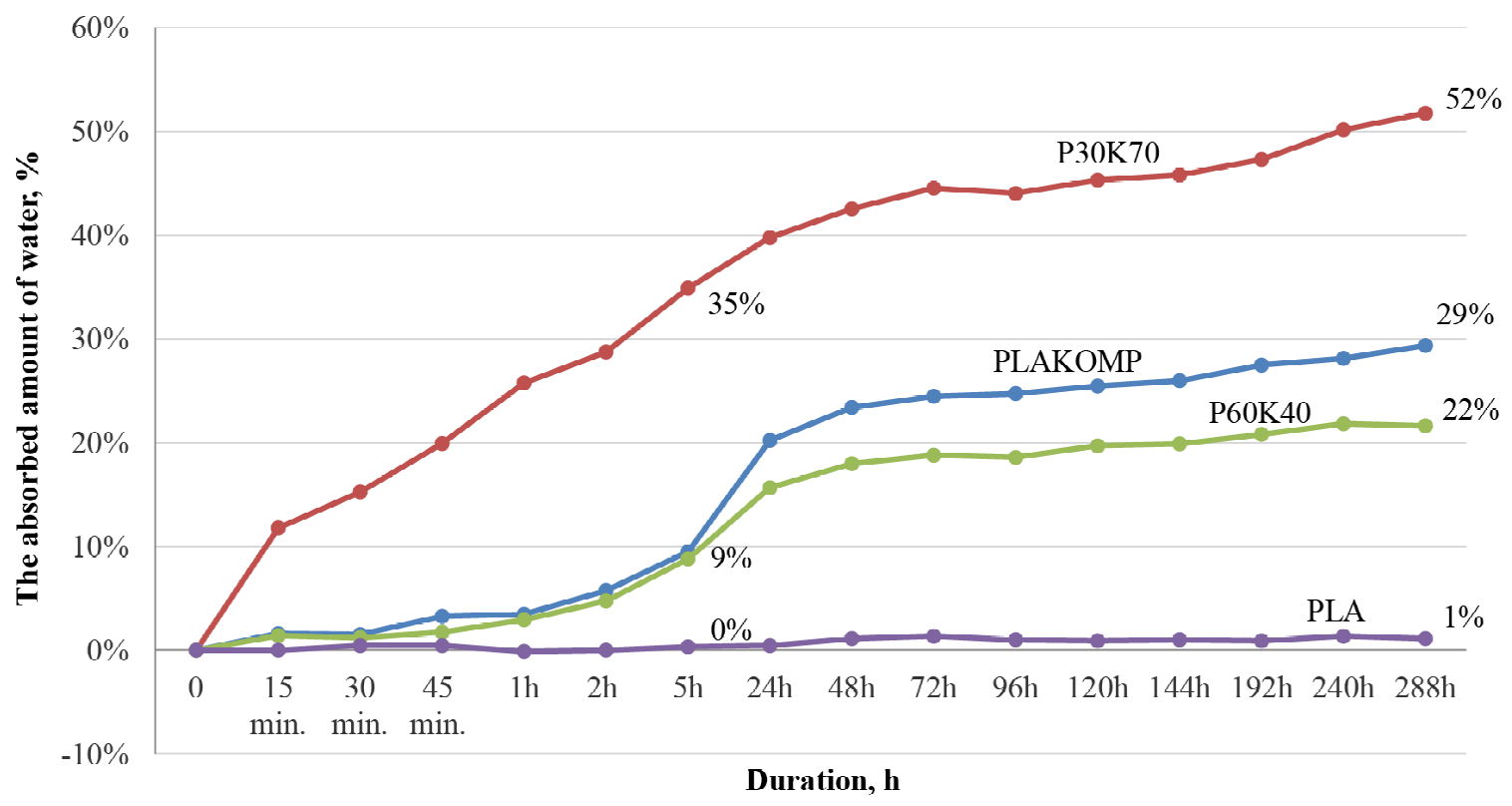

Fig. 3. Amount of water absorbed at 288 hours

The long-term results show that after $288 \mathrm{~h}$ the water absorption process has not yet been completed due to failure to achieve the absorption equilibrium values. Figure 3 shows that PLA is still undissolved in water, so the water absorption kinetics of composites depends on the hemp fibers.

As shown in Figure 4, after a week of absorption, the samples have slightly increased in size, the absorption dynamics are slow and water color change occurs. The PLA sample has become opaque, white.
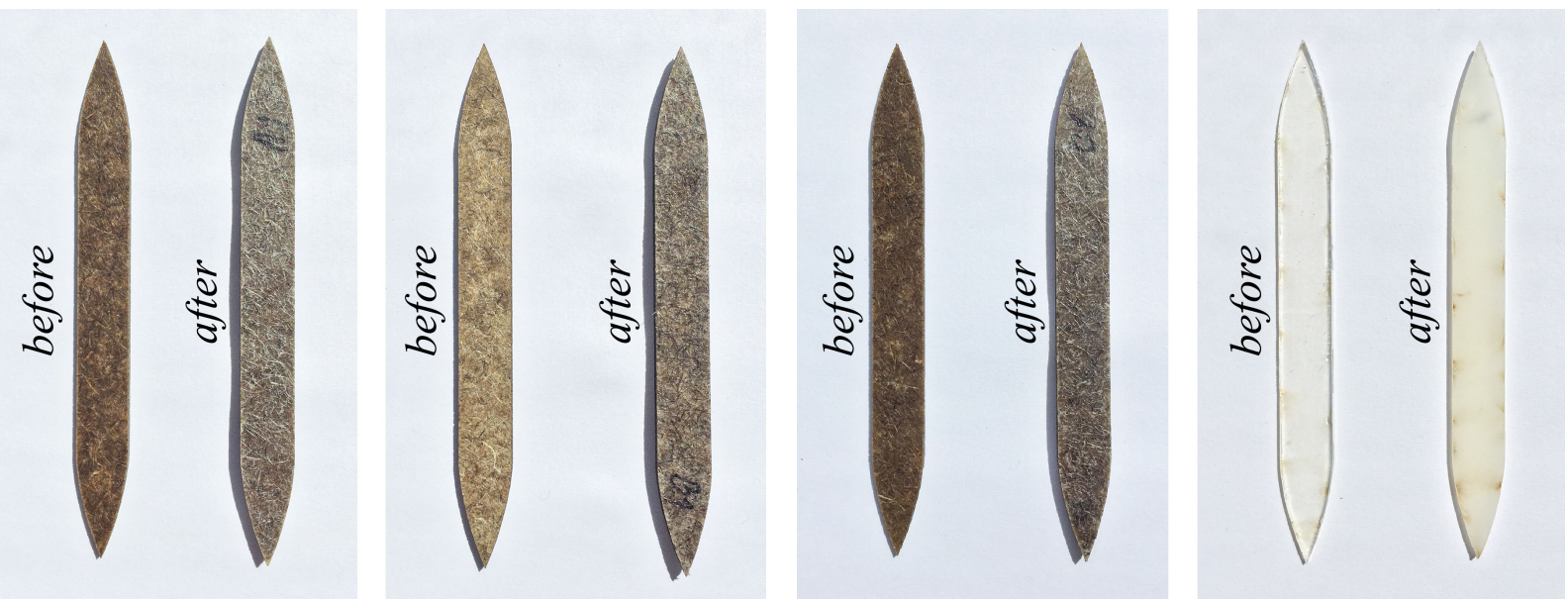

\section{PLAKOMP P30K70 P60K40 PLA}

Fig. 4. Photographic fixation of samples before and after water absorption test

\section{Conclusions}

1. According to the results of the water absorption test, bio-composite samples where the hemp fiber content is above $50 \%$ hemp fibers should be treated before incorporation to reduce their water absorption capacity.

2. Bio-composite samples with a fiber content below $50 \%$ show insignificant water absorption, which is considered a good result.

3. The long-term results show that PLA is still undissolved in water, so the water absorption kinetics of these bio-composites depends on the hemp fibers.

4. The obtained bio-composite manufacturing technology is appropriate to reach high absorption potential, which is one of the crucial factors to be taken into account for the biobased composites. 
5. The use of hemp fibre in biodegradable composites has the potential, because its reinforcement not only improves the mechanical properties of bio-composites and their use, but also improves the ecological assessment of the product.

\section{References}

[1] Pickering K. Properties and Performance of Natural-Fibre Composites. Woodhead Publishing in Materials, 2008. 272 p.

[2] Solizenko R. Hemp Fibres Properties and Use Feasibility in Polymer Composites. Riga Technical University, 2012. 13 p.

[3] "Kaṇepju audzēšanas potenciāls Latvijas ekonomikā". Latvian Industrial Hemp Association. [online] [15.12.2018]. Available at: http://lathemp.lv/?page_id $=178$

[4] Sipkovs P., Ivanovs S., Kukle S. Innovative technologies for heat and cold production and production of new products using local renewable energy resources. Riga, 2015. $42 \mathrm{p}$.

[5] Baillie C. Green Composites: Polymer Composites an the Environment. CRC Press, 2005, pp. 124-135.

[6] Wallenberger F.T., Weston N.E. Natural Fibers, Plastics and Composites. KJuwer Academic Publishers, 2004. pp. 149-164.

[7] Väisänen T., Batello P., Lappalainen R., Tomppo L. Modification of hemp fibers (Cannabis Sativa L.) for composite applications. Industrial Crops and Products, Volume 111, 2018. pp. 422-429.

[8] LVS EN ISO 62:2008 standard "Plastics - Determination of water absorption". 